\title{
Fast real-time monitoring of entacapone crystallization and characterization of polymorphs via Raman spectroscopy, statistics and SWAXS
}

\author{
TOMISLAV JEDNAČAK ${ }^{1}$ \\ ADEN HODZIC ${ }^{2}$ \\ OTTO SCHEIBELHOFER ${ }^{2}$ \\ MARIJAN MARIJAN ${ }^{1}$ \\ JOHANNES G. KHINAST ${ }^{2,3}$ \\ PREDRAG NOVAK ${ }^{1 *}$ \\ 1 University of Zagreb, Faculty of \\ Science, Department of Chemistry \\ HR-10000 Zagreb, Croatia \\ 2 Research Center Pharmaceutical \\ Engineering GmbH, A-8010 Graz, Austria \\ ${ }^{3}$ Institute for Particle and Process \\ Technology, A-8010 Graz, Austria
}

\begin{abstract}
Crystallization of the drug entacapone from binary solvent mixtures was monitored in situ using a Raman optical probe. The recorded Raman spectra and statistical analysis, which included the principal components method and indirect hard modeling made it possible to estimate the starting point of crystallization, to assess crystallization temperatures and to provide information on the polymorphic content of the mixture. It was established that crystallization temperatures were proportional to the volume content of the solvent in mixtures. The samples were also evaluated off-line via Raman spectroscopy and SWAXS. The collected data showed the presence of forms $\beta$ and $\gamma$ in all solvent mixtures. In a toluene/methanol 30:70 mixture, in addition to forms $\beta$ and $\gamma$, at least one of the forms A, D or $\alpha$ was also indicated by SWAXS. The results have shown that the presence of a particular polymorph is strongly dependent on the nature and portion of the solvent in the binary solvent mixture.
\end{abstract}

Keywords: entacapone, in-line crystallization monitoring, multivariate analysis, polymorphism, Raman spectroscopy, SWAXS

Many active pharmaceutical ingredients (APIs) are small organic molecules that have different polymorphic forms (1). It is well known that the API's polymorphic form can affect its physico-chemical properties, such as density, melting point, solubility, stability, morphology and bioavailability (2). Thus, polymorphic screening is a critical part of preformulation studies. The search for possible polymorphic forms typically begins with crystallization of a drug substance from various solvents, including those frequently used during the final crystallization steps $(3,4)$. Since the API's physicochemical properties can have a dramatic impact on its therapeutic effect, it is crucial to detect the polymorphic form with the characteristics appropriate for the intended use. For this purpose, the parameters affecting the crystallization process should be controlled and optimized (5). Major limitations to improving the control of crystallization parameters

\footnotetext{
* Correspondence; e-mail: pnovak@chem.pmf.hr
} 
a)<smiles>CCN(CC)C(=O)/C(C#N)=C/c1cc(O)c(O)c([N+](=O)[O-])c1</smiles>

b)<smiles>CCN(CC)C(=O)/C(C#N)=C\c1cc(O)c(O)c([N+](=O)[O-])c1</smiles>

Fig. 1. Chemical structures of: a) $E$ - and b) Z-isomers of entacapone.

are caused by the lack of accurate, robust and reliable in-line sensors and new methodologies based on timely measurements of process variables are required to improve the product efficacy and quality control.

Chemical reactions, wet granulation, dissolution, polymorphism and crystallization processes have already been investigated via in situ or in-line vibrational spectroscopy (6-11). Raman and infrared spectroscopy have been employed to investigate pharmaceutical crystal forms $(2,4,12)$. Due to the different ordering of atoms in the crystal lattice, each crystal form generally has different Raman and infrared spectra. Thus, the analysis of in-line Raman spectra obtained during the crystallization process could reveal polymorphic transformations as a function of time. Quantitative crystallization monitoring by in-line Raman spectroscopy usually involves the design of calibration models derived from the Raman spectra of pure solid-state forms (13-17).

However, the API crystals generally contain a mixture of different polymorphs (1) whose content cannot be exactly determined using vibrational spectroscopy alone. In such cases, the statistical analysis of in-line vibrational spectra is ultimately required (11, $18,19)$. Further insight both into the API content and the structure in the solid state can be obtained by off-line methods, and X-ray scattering techniques are ideal for this purpose. Thus, small and wide angle X-ray scattering techniques (SWAXS) have been used to assess the API and excipient content (20), to investigate the effects of process variables on the crystalline state of powders, granules and tablets (21) and to study interactions between the model's membranes and biologically active compounds $(22,23)$. This paper describes in-line crystallization monitoring of the drug entacapone via Raman spectroscopy and multivariate methods involving principal components analysis (PCA) and indirect hard modeling (IHM) as well as off-line characterization of the obtained polymorphic forms using Raman spectroscopy and SWAXS. Entacapone, i.e., 2-cyano- $N, N$-diethyl-3-(3,4-dihydroxy-5-nitrophenyl) propenamide, is a potent and selective inhibitor of COMT (catechol-O-methyltransferase), the enzyme responsible for the metabolism of L-dopa (3,4-dihydroxyphenyl-L-alanine), which is the precursor to dopamine (24). Entacapone is clinically used as a therapy for Parkinson's disease (25), which is associated with a lack of dopamine.

\section{EXPERIMENTAL}

\section{Materials}

Entacapone crystals ( $E$-isomer, form A) were obtained from PLIVA d.o.o. (Croatia). Methanol (min. $99.5 \%$ ) and acetone (min. $99.5 \%$ ) were purchased from Kemika d.d. (Croatia). Toluene (min. $99.5 \%$ ) was purchased from Carlo Erba Reagents SpA (Italy). 
T. Jednačak et al.: Fast real-time monitoring of entacapone crystallization and characterization of polymorphs via Raman spectroscopy, statistics and SWAXS, Acta Pharm. 64 (2014) 1-13.

\section{Entacapone crystallization}

Saturated solutions of entacapone were prepared by dissolving entacapone crystals (E-isomer, form A) in acetone/water $\left(40: 60\right.$ and 30:70, V/V; $2 \mathrm{~g}$ in $\left.200 \mathrm{~mL} ; T=74.5^{\circ} \mathrm{C}\right)$ and toluene/methanol (30:70 and 20:80, $V / V ; 20 \mathrm{~g}$ in $\left.200 \mathrm{~mL} ; \mathrm{T}=65.0^{\circ} \mathrm{C}\right)$ mixtures. The solvents were chosen according to the solubility of entacapone and the fact that they were common solvents used in the production process (26-28).

Temperatures were selected according to the solubility of entacapone in acetone/ water and toluene/methanol mixture, respectively. The obtained solutions were stirred at $300 \mathrm{rpm}$ in the laboratory reactor until entacapone crystals dissolved completely. The solutions were then gradually cooled using the thermostatic bath Lauda-alpha RA 12 (Lauda Dr. R. Wobser GmbH \& Co., Germany) coupled to a laboratory reactor. The cooling rate decreased linearly with the temperature.

Hence, the cooling curves of entacapone in the acetone/water and toluene/methanol solutions were approximated using Eqs. (1) and (2):

$$
\begin{aligned}
& T=74.51-0.823 t+0.002 t^{2} \\
& T=64.96-0.770 t+0.002 t^{2}
\end{aligned}
$$

where $T\left({ }^{\circ} \mathrm{C}\right)$ is the temperature in the thermostatic bath and $t(\mathrm{~min})$ is the time. The parameters in Equations (1) and (2) were calculated via linear regression of the data collected every $1{ }^{\circ} \mathrm{C}$ at appropriate time intervals. The coefficient of determination $\left(R^{2}\right)$ was 0.9998 for both equations.

\section{Raman spectroscopy}

A Bruker Equinox interferometer equipped with a FRA 106/S Raman module (Bruker Optics GmbH, Germany) was used for monitoring the crystallization and characterization of entacapone crystals. NIR excitation was provided by Nd-YAG laser $(\lambda=1064$ $\mathrm{nm}, P=500 \mathrm{~mW})$. The in-line Raman spectra were collected in real-time $(3.7 \mathrm{~min}$ per spectrum) during the crystallization process using a fiber-optic immersion probe (Bruker Optics $\mathrm{GmbH}$, Germany). Experiments were repeated three times under identical conditions. Off-line Raman spectra of the filtered entacapone crystals were also recorded. Each spectrum was acquired by averaging 128 scans with a resolution of $4 \mathrm{~cm}^{-1}$ in the range between 3500 and $100 \mathrm{~cm}^{-1}$.

\section{Principal components analysis}

Raman data were recorded using the OPUS program from Bruker Optics and further processed using The Unscrambler 10.2 software (CAMO Software AS, Oslo, Norway). A subset of spectral data in the range between 2300 and $850 \mathrm{~cm}^{-1}$ was selected. As it could not be guaranteed that the optical path length was always the same, SNV (standard normal variate) was performed across this region in order to normalize the spectra. PCA was performed with normalized and centred spectra. 
T. Jednačak et al.: Fast real-time monitoring of entacapone crystallization and characterization of polymorphs via Raman spectroscopy, statistics and SWAXS, Acta Pharm. 64 (2014) 1-13.

\section{Indirect hard modelling}

Calibration spectra were obtained by processing the off-line Raman spectra of pure polymorphic forms of entacapone using programs developed in Matlab v7.1 (The Mathworks Inc., Natick, MA, USA). The first recorded in-line Raman spectrum in each solvent was used as the background. Pretreatments for the calibration spectra and in-line Raman spectra of entacapone crystallization were as follows. A subset of spectral data in the range between 1688 and $1158 \mathrm{~cm}^{-1}$ was selected. Linear baseline correction, SNV (standard normal variate) and Savitzky-Golay smoothing over 15 points were performed across this spectral range. The spectra were corrected to the lowest value in order to exclude negative regions.

In the next step, calibration spectra were modeled by indirect hard modeling. The in-line Raman spectra were approximated by a linear combination of model spectra. The relative intensity coefficients were proportional to the concentrations of entacapone polymorphic forms.

\section{SWAXS measurements}

SWAXS employs two separate detectors, which identify different properties of the sample and simultaneously collect scattered X-ray spectra from a single sample at small (SAXS) and wide (WAXS) angles. The signal in SAXS spectra is a result of electron density differences in the sample (29), while the WAXS spectra detect fingerprints originating from crystalline structure of the components.

A high-resolution SWAXS camera (Hecus S3-Micropix, Austria) with point-focus optics (FOX3D) and a high-brilliance micro-beam delivery system, operated at $50 \mathrm{kV}$ and $1 \mathrm{~mA}$, was utilized for our experiments. The SAXS and WAXS spectra were collected with two independent 1D-detectors (PSD-50, Hecus X-ray Systems, Austria) in the angular ranges of $0.06^{\circ}<2 \theta<8^{\circ}$ and $17^{\circ}<2 \theta<27^{\circ}$, respectively.

The powder sample $(85 \mathrm{mg}$ ) was placed in a glass capillary with an internal diameter of $2 \mathrm{~mm}$ sealed with wax. The capillary was rotated while being exposed to an X-ray beam to allow for angular averaging of the powder scattering patterns. Triplicate measurements were performed at room temperature by exposing the samples for $700 \mathrm{~s}$ to an X-ray beam with a diameter of $200 \mu \mathrm{m}$ and a wavelength of $1.542 \AA$. The obtained data were normalized using the sample with the highest value.

\section{RESULTS AND DISCUSSION}

The entacapone synthesis reaction produces two isomers, $E$ - and Z- (Fig. 1), in the relative ratio of 2:1 (6), but only $E$ - isomer is used as API, since it can be easily isolated from the reaction mixture. Full Surface-enhanced Raman spectroscopy (SERS) has been recently used for quantitative analysis of the two isomers in solution (30). It has also been demonstrated that the $E$-isomer crystallizes in six polymorphic forms, named $\mathrm{A}^{\prime}$ (25), D (26), $\alpha, \beta, \gamma$ and $\delta$ (27), the first two being the most common in polar solvents (28). Furthermore, form A has been found to be the most stable phase thermodynamically. 
T. Jednačak et al.: Fast real-time monitoring of entacapone crystallization and characterization of polymorphs via Raman spectroscopy, statistics and SWAXS, Acta Pharm. 64 (2014) 1-13.

\section{In-line crystallization monitoring}

The in-line Raman spectra were continuously collected during the crystallization process in two binary solvent mixtures, viz., acetone/water and toluene/methanol. Measurements were performed at different levels in the laboratory reactor to obtain the most intense signals. Representative in-line Raman spectra of entacapone crystallization from the acetone/water 40:60 and toluene/methanol 30:70 solutions are shown in Fig. 2.

Raman bands that appeared in the spectra during the temperature decrease indicated the beginning of entacapone crystallization (Fig. 2). The vibrational band around $2200 \mathrm{~cm}^{-1}$ was attributed to the $\mathrm{C} \equiv \mathrm{N}$ stretching vibration characteristic of entacapone (6, 30). Moreover, two bands observed at $c a 1600$ and $1580 \mathrm{~cm}^{-1}$ in the in-line Raman spectra obtained in the acetone/water 40:60 and toluene/methanol 30:70 solutions (Fig. 2) were assigned to the amide $\mathrm{C}=\mathrm{O}$ and $\mathrm{C}=\mathrm{C}$ stretching mode, respectively. The vibrational band at $c a 1545 \mathrm{~cm}^{-1}$ corresponds to asymmetrical $\mathrm{N}-\mathrm{O}$ stretching mode. Furthermore, a strong band observed at $\mathrm{ca} 1440 \mathrm{~cm}^{-1}\left(\delta \mathrm{CH}_{2}\right)$ further confirmed the formation of entacapone crystals in the acetone/water and toluene/methanol solutions $(6,30)$.

However, the severe band overlap and low signal-to-noise ratio in the in-line Raman spectra prevented unambiguous determination of crystallization temperatures directly from the spectra. Hence, we utilized the principal component analysis to analyze the spectra and to assign other vibrational bands. Representative score and loading plots for entacapone crystallization from the acetone/water 40:60 and toluene/methanol 30:70 solutions are displayed in Figs. 3 and 4. The first principal component (PC1) described the greatest extent of variance, thus giving a satisfactory description of the crystallization process in all the solvents used. Crystallization temperatures were determined from the score plots and are summarized in Table I. As shown in the PC1 scores (Figs. 3a and 4a), entacapone crystallized at higher temperature in the acetone/water 40:60 $\left(18{ }^{\circ} \mathrm{C}\right)$ than in the toluene/methanol 30:70 solution $\left(7^{\circ} \mathrm{C}\right)$, pointing to the different influence of solvent ratio on crystallization temperature. In the case of acetone/water 30:70 and toluene/methanol 20:80 solutions, crystallization started at approx. 30 and $9{ }^{\circ} \mathrm{C}$, respectively. This is in agreement with low entacapone solubility in water and methanol and indicates that crystallization temperature is proportional to their volume content in solvent mixtures.

The spectral features responsible for the score plot in Fig. 3a are displayed in the loading plot (Fig. 3b). Positive peaks in the loading spectrum at 2218, 1602 and $1581 \mathrm{~cm}^{-1}$

Table I. Entacapone crystallization temperatures in acetone/water and toluene/methanol solutions as determined from the score plots

\begin{tabular}{cc}
\hline Solvent mixture & $T(\mathrm{EC})$ \\
\hline Acetone/water 40:60 $(V / V)$ & 18 \\
Acetone/water 30:70 $(V / V)$ & 30 \\
Toluene/methanol 30:70 $(V / V)$ & 7 \\
Toluene/methanol 20:80 $(V / V)$ & 9 \\
\hline
\end{tabular}


correspond to $\mathrm{C} \equiv \mathrm{N}$, amide $\mathrm{C}=\mathrm{O}$ and $\mathrm{C}=\mathrm{C}$ stretching band, respectively, present in the in-line Raman spectra (Fig. 2a). Furthermore, a strong peak at $1442 \mathrm{~cm}^{-1}$, whose intensity increased during the crystallization process, was attributed to the $\mathrm{CH}_{2}$ bending vibration characteristic of entacapone. Additional peaks at 1346, 1278 and $1202 \mathrm{~cm}^{-1}$ further confirmed the presence of entacapone crystals. Similar bands were observed in the other solvent mixture (Fig. $4 \mathrm{~b}$ ). Hence, the appearance of negative $\mathrm{CH}_{2}$ bending and positive $\mathrm{C} \equiv \mathrm{N}$ stretching bands in the loading plots in Fig. $4 \mathrm{~b}$ provided clear evidence for entacapone crystallization from the toluene/methanol 30:70 solution.

Subsequent analysis of in-line Raman spectra provided preliminary information for the identification of specific polymorphic forms. As seen in Fig. 2, entacapone crystallized from the acetone/water 40:60 solution showed in-line Raman bands at approx. 1600, 1580 and $1345 \mathrm{~cm}^{-1}$, characteristic of the polymorphic forms $\beta$ and $\gamma$ (Fig. 6) indicating their presence in the sample. In-line Raman spectra recorded in acetone/water 30:70 and
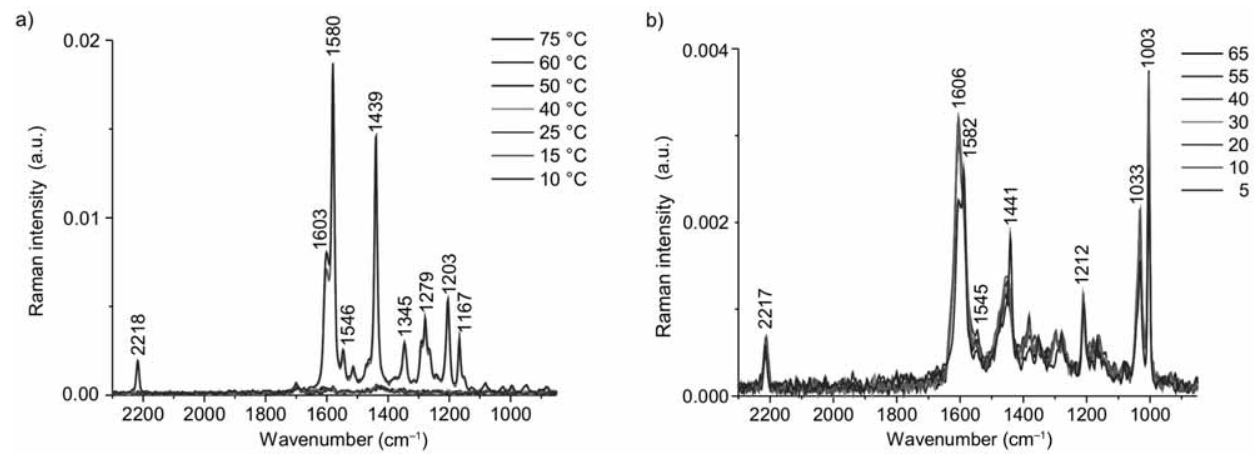

Fig. 2. Representative in line Raman spectra of entacapone crystallization from: a) acetone/water 40:60 and b) toluene/methanol 30:70 solutions.

a)

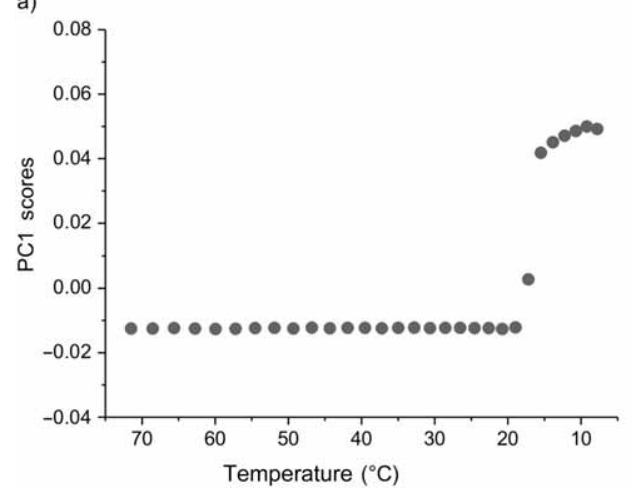

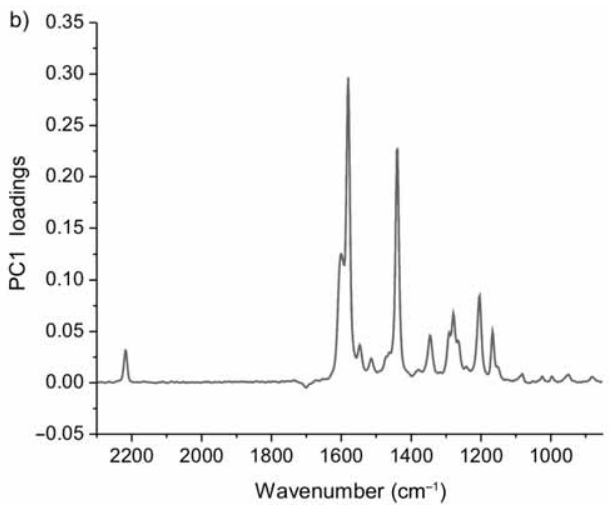

Fig. 3. a) PC1 scores and b) PC1 loadings for a set of 30 in-line Raman spectra of entacapone crystallization from acetone/water 40:60 solution. 

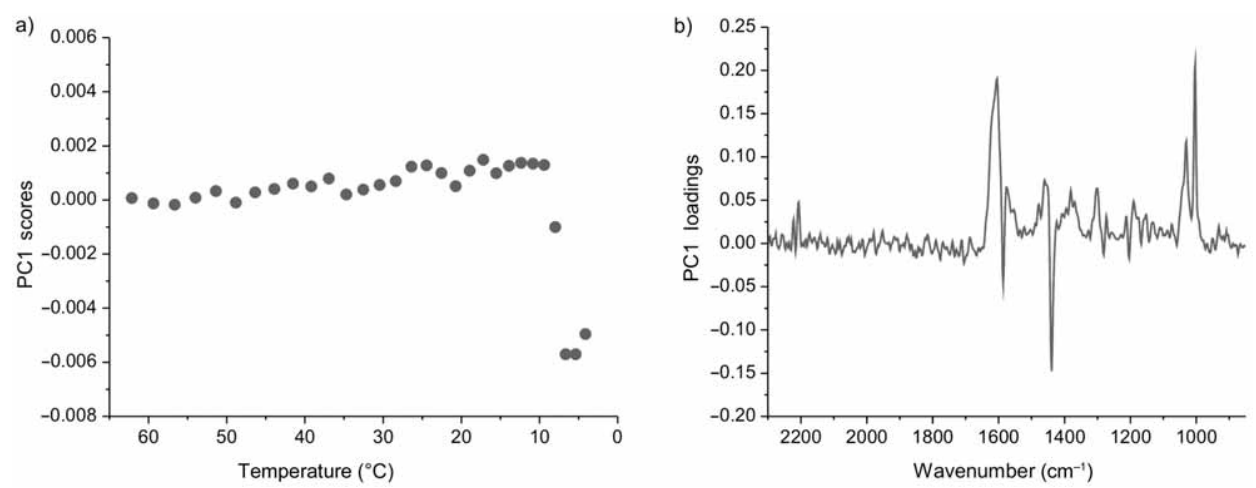

Fig. 4. a) PC1 scores and b) PC1 loadings for a set of 30 in-line Raman spectra of entacapone crystallization from the toluene/methanol 30:70 solution.

toluene/methanol 20:80 and 30:70 solutions exhibited low signal-to-noise ratio and severe band overlapping and straightforward identification of polymorphs was not possible. In order to resolve these ambiguities, the spectra were further analyzed using the indirect hard modelling method (IHM) to obtain further information on the polymorphic content during the crystallization process.

The IHM method was proved useful for the analysis of mixture constituents in cases of strongly overlapping spectral bands and nonlinear effects $(16,17)$. Hence, in-line Raman spectra of entacapone crystallization were approximated by the linear combination of pure component models using the IHM approach. The concentration of each polymorphic form in the mixture was represented by its relative intensity coefficient. Fig. 5a shows time variations of relative intensity coefficients for crystallization from the acetone/water 40:60 solution. Since polymorphic forms $\delta, \beta$ and $\gamma$ exhibited similar in-line Raman bands, their concentrations were represented by the sum of individual relative intensity coefficients. For the same reason, the relative intensity coefficient shown in Fig. 5
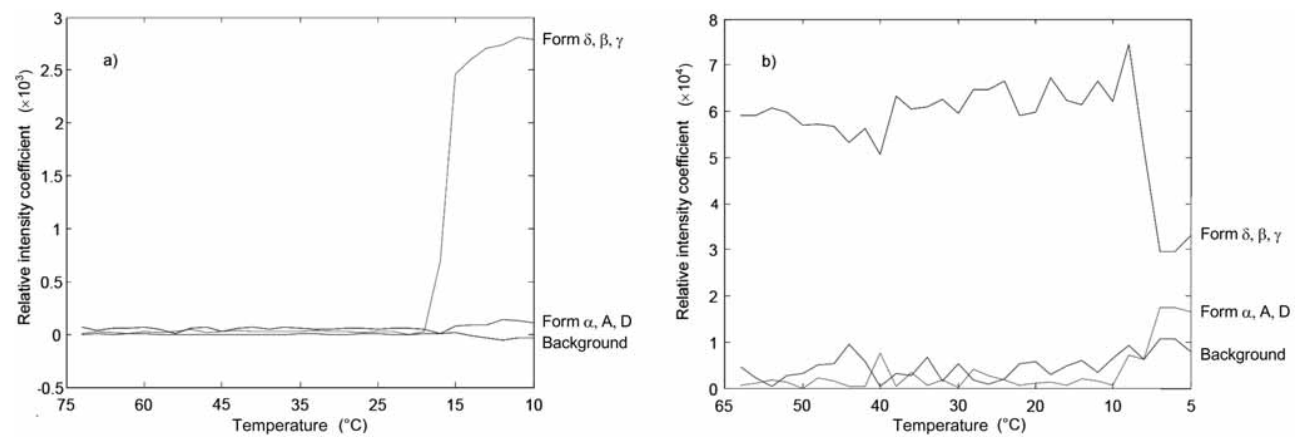

Fig. 5. Relative intensity coefficients for different polymorphic forms of entacapone during crystallization from: a) acetone/water 40:60 and b) toluene/methanol 30:70 solution. 
T. Jednačak et al.: Fast real-time monitoring of entacapone crystallization and characterization of polymorphs via Raman spectroscopy, statistics and SWAXS, Acta Pharm. 64 (2014) 1-13.

corresponds to the sum of polymorphic forms $\alpha, \mathrm{A}$ and D. Since for the latter three forms no change in coefficient was observed, it was concluded that these forms were not present in the sample. However, crystallization from the acetone/water 40:60 solution resulted only in a change of the relative intensity coefficient for polymorphic forms $\delta, \beta$ and $\gamma$ (Fig. 5a), indicating that at least one of these forms was present.

Similar results were obtained for crystallization from the acetone/water 30:70 and toluene/methanol 20:80 solutions. Owing to the fact that both coefficients, namely for forms $\alpha, \mathrm{A}$ and $\mathrm{D}$, and $\delta, \beta$ and $\gamma$, slightly increased during crystallization from the toluene/methanol 30:70 solution, it was not possible to determine the polymorphic content precisely. However, data presented in Fig. 5b indicated the presence of at least two different polymorphic forms. Hence, the samples were further analyzed off-line by Raman spectroscopy and SWAXS.

\section{Off-line characterization of polymorphic forms}

The off-line Raman spectra of entacapone pure polymorphic forms and of the crystals obtained from the acetone/water and toluene/methanol solutions are shown in Fig. 6. The most pronounced differences between the polymorphic forms were found in the spectral region 1610-1100 $\mathrm{cm}^{-1}$. The Raman spectra of polymorphic forms A, D and $\alpha$

Fig. 6. Off-line Raman spectra of pure polymorphic forms of entacapone and crystals obtained from (1) acetone/water 40:60, (2) acetone/water 30:70, (3) toluene/methanol 30:70 and (4) toluene/ methanol 20:80 solutions.

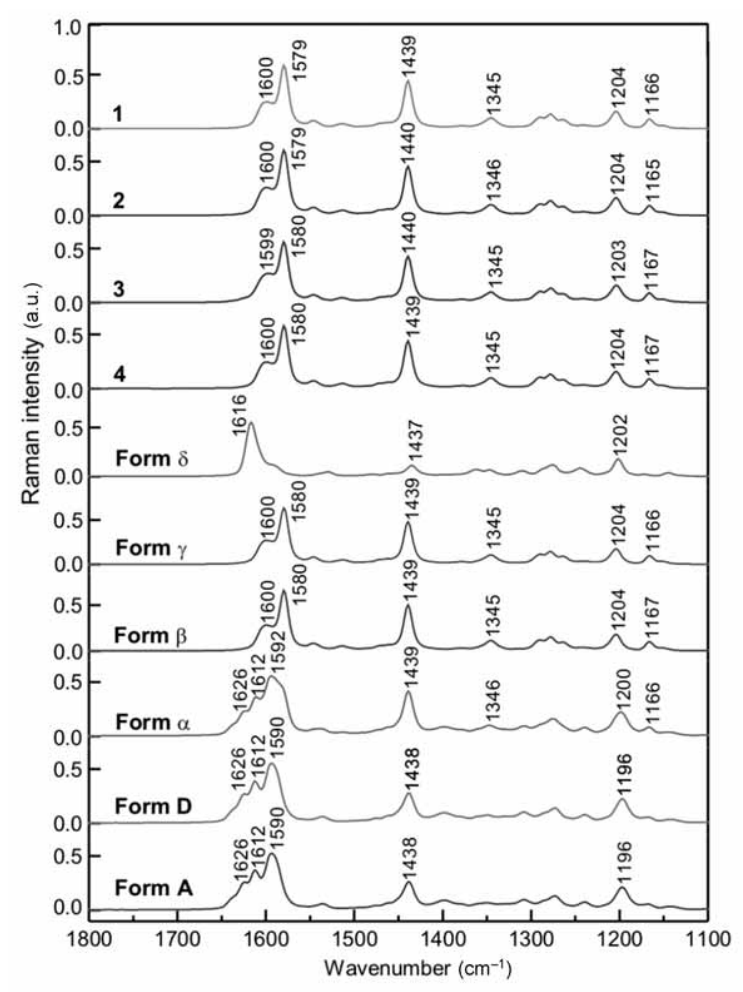


showed high similarity. The prominent features were strong vibrational bands at 1612 and $1590 \mathrm{~cm}^{-1}$, assigned to amide $\mathrm{C}=\mathrm{O}$ and $\mathrm{C}=\mathrm{C}$ stretching vibration, respectively. These bands shifted to lower wavenumbers in the Raman spectra of polymorphic forms $\beta$ and $\gamma$. In contrast, polymorphic form $\delta$ exhibited strong amide $C=O$ and weak $C=C$ stretching bands, both of which shifted to higher wavenumbers (Fig. 6). A strong combination band characteristic of $E$-isomer of entacapone $(6,30)$ was observed at ca $1438 \mathrm{~cm}^{-1}$. Several weak bands occurred at lower frequencies in the spectral region $1400-1100 \mathrm{~cm}^{-1}$ and can be attributed to $\mathrm{C}-\mathrm{C}, \mathrm{C}-\mathrm{O}$ and $\mathrm{C}-\mathrm{N}$ stretching vibrations.

As seen in Fig. 6, the off-line Raman spectra of entacapone crystals obtained from all solvent mixtures were almost identical, reflecting similar polymorphic composition of the samples.

The intensity and position of vibrational bands present in the spectra are characteristic of polymorphic forms $\beta$ and $\gamma$, which is in agreement with the in-line data. This indicates that forms $\beta$ and/or $\gamma$ were dominant polymorphic forms in the samples obtained from the acetone/water and toluene/methanol solutions. To further characterize all the forms present, SAXS and WAXS analyses were performed. Fig. 7 compares the SAXS spectra of entacapone crystals obtained from the acetone/water and toluene/methanol solutions with the SAXS spectra of pure polymorphic forms.

The spectra show the logarithm of scattering intensity $(\log I)$ versus the scattered vector $(q)$, which is related to the scattering angle $2 \theta$ by $q=4 \pi \sin \theta / \lambda$. As indicated in Fig. 7, the crystallinity peak that was observed at $q=0.48 \AA^{-1}$ was common for polymorphic forms A, D and $\alpha$, while the peak at $q=0.42 \AA^{-1}$ was characteristic of the polymorphic form $\delta$. In contrast, polymorphic forms $\beta$ and $\gamma$ did not have any peak in the SAXS region. As can be seen from Fig. 7, in the SAXS spectrum of entacapone crystals obtained from the toluene/methanol 30:70 solution, the Bragg peak characteristic of polymorphic forms A, D and $\alpha$ can be observed (see the arrow in Fig. 7). However, the entacapone crystals obtained from the acetone/water 30:70 and 40:60 and toluene/ methanol 20:80 solutions (1, 3 and 4, Fig. 7) did not show characteristic peaks in the SAXS

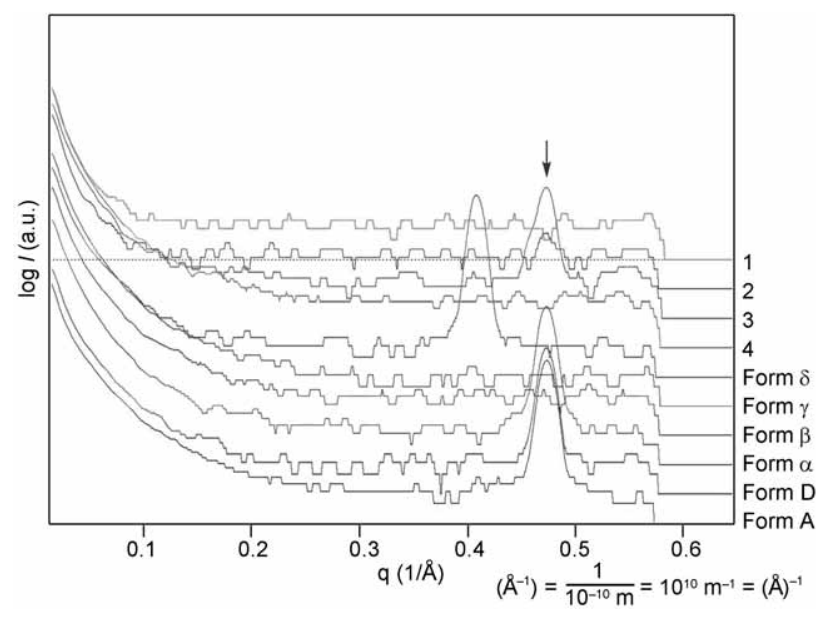

Fig. 7. SAXS spectra (logarithmic scale) of pure polymorphic forms of entacapone and crystals obtained from (1) acetone/water 40:60, (2) acetone/water 30:70, (3) toluene/methanol 30:70 and (4) toluene/methanol 20:80 solutions. The arrow points to the peak characteristic of polymorphic forms A, D and $\alpha$. 


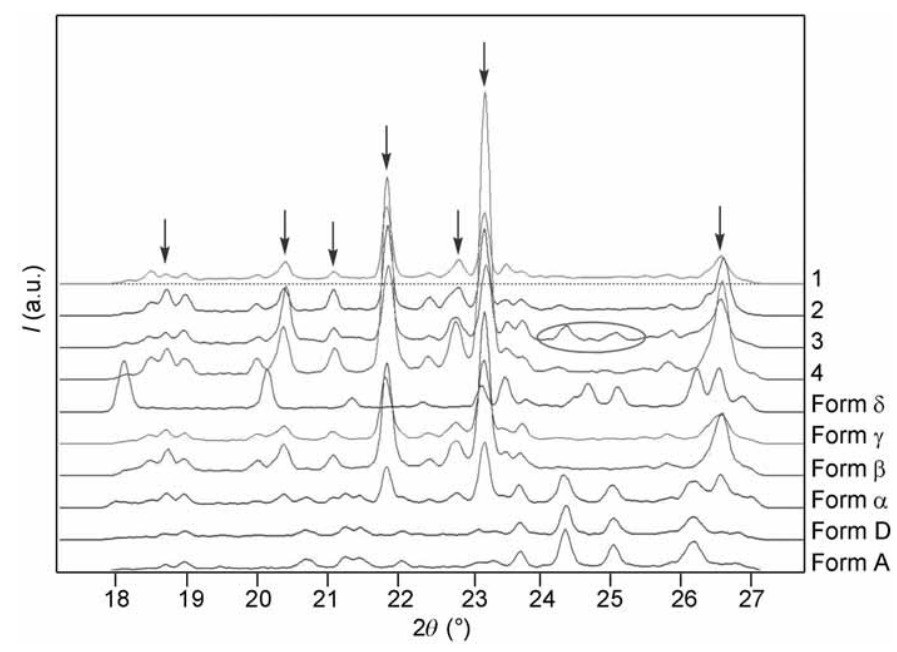

Fig. 8. WAXS spectra of pure polymorphic forms of entacapone and crystals obtained from (1) acetone/water 40:60 (2) acetone/water 30:70 (3) toluene/methanol 30:70 and (4) toluene/methanol 20:80 solutions. The peaks characteristic of polymorphic forms $\beta$ and $\gamma$ are indicated by arrows. The WAXS fingerprint corresponding to polymorphic forms A, D and $\alpha$ is circled.

region, which indicated the presence of polymorphic forms $\beta$ and $\gamma$, as already concluded from the Raman spectra.

This finding was supported by the analysis of WAXS fingerprints characteristic of particular crystalline forms (Fig. 8). The WAXS spectra, collected simultaneously with the SAXS spectra, showed the scattering intensity $(I)$ versus the scattering angle $(2 \theta)$. As indicated by arrows in Fig. 8, entacapone crystals obtained from the acetone/water and toluene/methanol solutions had crystallinity peaks at 18.84, 20.23, 20.46, 21.20, 22.51, 22.92 and $26.61^{\circ}$, which was characteristic of pure polymorphic forms $\beta$ and $\gamma$.

However, entacapone crystals obtained from the toluene/methanol 30:70 solution had additional Bragg peaks between 24.5 and 25.5E (marked in Fig. 8) that could correspond to either of the polymorphic forms $\mathrm{A}, \mathrm{D}$ or $\alpha$, which was in agreement with the SAXS spectra. Hence, apart from $\beta$ and $\gamma$, the sample additionally contained at least one of the forms A, D and $\alpha$. If existing, forms A, D or $\alpha$ had to be present in a very low amount since no characteristic vibrational bands were observed in in-line Raman spectra. In other cases, crystallization was more selective, yielding a mixture of only 2 polymorphic forms ( $\beta$ and $\gamma$ ). Hence, the appearance of a particular polymorph is dependent on the nature and the ratio of the solvents used for crystallization.

\section{CONCLUSIONS}

Crystallization of entacapone from binary solvent mixtures was investigated using in-line Raman spectroscopy and multivariate analysis, which proved to be a suitable and 
T. Jednačak et al.: Fast real-time monitoring of entacapone crystallization and characterization of polymorphs via Raman spectroscopy, statistics and SWAXS, Acta Pharm. 64 (2014) 1-13.

fast approach for monitoring the crystallization process in real time. The starting points of crystallization and temperatures were determined in acetone/water and toluene/methanol solutions. Analysis of characteristic in-line Raman bands indicated the presence of different polymorphic forms. In-line Raman spectra were further evaluated by statistical methods to allow for characterization of polymorphic forms present in crystallized samples. Off-line analysis by Raman spectroscopy and SWAXS corroborated the polymorphic content indicated by in-line methods. Hence, forms $\beta$ and $\gamma$ were found to be dominant polymorphs in all the binary solvent mixtures used. Collected data also pointed to the presence of at least one of the forms A, D or $\alpha$ in the toluene/methanol 30:70 solution.

This study has demonstrated that in-line Raman spectroscopy coupled with statistical methods is a powerful and fast approach for monitoring and characterizing the crystallization process of entacapone and that it can potentially be used for in-process quality control.

Acknowledgements. - The authors thank Eva-Maria Saurugger for performing SWAXS measurements and Ana Kwokal for her helpful comments and suggestions. Financial support for this work was provided by the Croatian Science Foundation, Pliva d.d., Ministry of Science, Education and Sports of the Republic of Croatia (Project No. 119-1191342-1083), Scholarship Foundation of the Republic of Austria for Undergraduates, Graduates und Postgraduates.

\section{REFERENCES}

1. R. Hilfiker, F. Blatter and M. von Raumer, Relevance of Solid-state Properties for Pharmaceutical Products, in Polymorphism in the Pharmaceutical Industry (Ed. R. Hilfiker), $1^{\text {st }}$ ed., John Wiley \& Sons Inc., Weinheim 2006, pp. 1-19.

2. W. P. Findlay and D. E. Bugay, Utilization of Fourier transform-Raman spectroscopy for the study of pharmaceutical crystal forms, J. Pharm. Biomed. Anal. 16 (1998) 921-930; DOI: 10.1016/ S0731-7085(97)00058-7.

3. B. Yu. Shekunov and P. York, Crystallization processes in pharmaceutical technology and drug delivery design, J. Cryst. Growth 211 (2000) 122-136; DOI: 10.1016/S0022-0248(99)00819-2.

4. M. C. Gamberini, C. Baraldi, A. Tinti, C. Rustichelli, V. Ferioli and G. Gamberini, Solid state characterization of chloramphenicol palmitate. Raman spectroscopy applied to pharmaceutical polymorphs, J. Mol. Str. 785 (2006) 216-224; DOI: 10.1016/j.molstruc.2005.10.012.

5. W. Beckmann, Seeding the desired polymorph: background, possibilities, limitations and case studies, Org. Process Res. Dev. 4 (2000) 372-383; DOI: 10.1021/op0000778.

6. P. Novak, A. Kišić, T. Hrenar, T. Jednačak, S. Miljanić and G. Verbanec, In-line reaction monitoring of entacapone synthesis by Raman spectroscopy and multivariate analysis, J. Pharm. Biomed. Anal. 54 (2011) 660-666; DOI: 10.1016/j.jpba.2010.10.012.

7. T. De Beer, A. Burggraeve, M. Fonteyne, L. Saerens, J. P. Remon and C. Vervaet, Near infrared and Raman spectroscopy for the in-process monitoring of pharmaceutical production processes, Int. J. Pharm. 417 (2011) 32-47; DOI: 10.1016/j.ijpharm.2010.12.012.

8. H. Wikström, P. J. Marsac and L. S. Taylor, In-line monitoring of hydrate formation during wet granulation using Raman spectroscopy, J. Pharm. Sci. 94 (2004) 209-219; DOI: 10.1002/jps.20241. 
T. Jednačak et al.: Fast real-time monitoring of entacapone crystallization and characterization of polymorphs via Raman spectroscopy, statistics and SWAXS, Acta Pharm. 64 (2014) 1-13.

9. S. Šašić, A. S. Palm and D. Tang, Monitoring the dissolution of active pharmaceutical ingredient and TGPS in real time via IR spectroscopy during the manufacturing of liquid dosage formulation, J. Pharm. Biomed. Anal. 70 (2012) 273-279; DOI: 10.1016/j.jpba.2012.07.010.

10. G. Févotte, In situ Raman spectroscopy for in-line control of pharmaceutical crystallization and solids elaboration processes: A review, Chem. Eng. Res. Des. 85 (A7) (2007) 906-920; DOI: 10.1205/ cherd06229.

11. L. X. Yu, R. A. Lionberger, A. S. Raw, R. D'Costa, H. Wu and A. S. Hussain, Applications of process analytical technology to crystallization processes, Adv. Drug Deliv. Rev. 56 (2003) 349-369; DOI: 10.1016/j.addr.2003.10.012.

12. J. Aaltonen, K. C. Gordon, C. J. Strachan and T. Rades, Perspectives in the use of spectroscopy to characterise pharmaceutical solids, Int. J. Pharm. 364 (2008) 159-169; DOI: 10.1016/j.ijpharm. 2008.04.043.

13. C. Starbuck, A. Spartalis, L. Wai, J. Wang, P. Fernandez, C. M. Lindemann, G. X. Zhou and Z. $\mathrm{Ge}$, Process optimization of a complex pharmaceutical polymorphic system via in situ Raman spectroscopy, Cryst. Growth Des. 2 (2002) 515-522; DOI: 10.1021/cg025559k.

14. T. Ono, J. H. ter Horst and J. Jansens, Quantitative measurement of the polymorphic transformation of L-glutamic acid using in-situ Raman spectroscopy, Cryst. Growth Des. 4 (2004) 465-469; DOI: $10.1021 / \operatorname{cg} 0342516$.

15. C. J. Strachan, T. Rades, K. C. Gordon and J. Rantanen, Raman spectroscopy for quantitative analysis of pharmaceutical solids, J. Pharm. Pharmacol. 59 (2010) 179-192; DOI: 10.1211/jpp.59. 2.0005 .

16. E. Kriesten, D. Mayer, F. Alsmeyer, C. B. Minnich, L. Greiner and W. Marquardt, Identification of unknown pure component spectra by indirect hard modeling, Chemom. Intell. Lab. Syst. 93 (2008) 108-119; DOI: 10.1016/j.chemolab.2008.05.002.

17. J. Li and L. Dai, A hard modeling approach to determine methanol concentration in methanol gasoline by Raman spectroscopy, Sens. Actuat. B 173 (2012) 385-390; DOI: 10.1016/j.snb.2012. 07.012 .

18. N. Chieng, T. Rades and J. Aaltonen, An overview of recent studies on the analysis of pharmaceutical polymorphs, J. Pharm. Biomed. Anal. 55 (2011) 618-644; DOI: 10.1016/j.jpba.2010.12.020.

19. K. Kogermann, J. Aaltonen, C. J. Strachan, K. Pöllänen, P. Veski, J. Heinämäki, J. Yliruusi and J. Rantanen, Qualitative in situ analysis of multiple solid-state forms using spectroscopy and partial least squares discriminant modeling, J. Pharm. Sci. 96 (2007) 1802-1820; DOI: 10.1002/jps. 20840.

20. A. Hodzic, M. Llusa, S. D. Fraser, O. Scheibelhofer, D. M. Koller, F. Reiter, P. Laggner and J. G. Khinast, Small and wide-angle X-ray scattering (SWAXS) for quantification of aspirin content in a binary powder mixture, Int. J. Pharm. 428 (2012) 91-95; DOI: 10.1016/j.ijpharm.2012.02.048.

21. A. Hodzic, M. Llusa, N. Heigl, W. Tritthart, S. D. Fraser, P. Laggner and J. G. Khinast, Effect of process variables on the small and wide angle X-ray scattering (SWAXS) patterns of powders, granules and pharmaceutical tablets, Powder Technol. 221 (2012) 447-452; DOI: 10.1016/j.powtec. 2012.01.043.

22. A. Hodzic, P. Zoumpoulakis, G. Pabst, T. Mavromoustakos and M. Rappolt, Losartan's affinity to fluid bilayers modulates lipid-cholesterol interactions, Phys. Chem. Chem. Phys. 14 (2012) 4780-4788; DOI: $10.1039 /$ c2cp40134g.

23. M. Köberl, H. J. Hinz and G. Rapp, Temperature scanning simultaneous small- and wide- X-ray scattering studies on glycolipid vesicles: areas, expansion coefficients and hydration, Chem. Phys. Lipids 91 (1998) 13-37; DOI: 10.1016/S0009-3084(97)00091-1.

24. P. T. Männisto and S. Kaakkola, Catechol-O-metyltransferase (COMT) biochemistry, molecular biology, pharmacology, and clinical efficiacy of the new selective COMT inhibitors, Pharmacol. Rev. 51 (1999) 593-628. 
T. Jednačak et al.: Fast real-time monitoring of entacapone crystallization and characterization of polymorphs via Raman spectroscopy, statistics and SWAXS, Acta Pharm. 64 (2014) 1-13.

25. J. Leppänen, E. Wegelius, T. Nevalainen, T. Järvinen, J. Gynther and J. Huuskonen, Structural studies of acyl esters of entacapone, J. Mol. Struct. 562 (2001) 129-135; DOI: 10.1016/S0022-2860 (00)00859-0.

26. M. S. M. Jaweed, R. A. R. Khan, R. P. Yadav and Z. G. Shaikh, Stable Polymorphs of $(E)-N, N-$ diethyl-2-cyano-3-(3,4-dihydroxy-5-nitrophenyl)acrylamide, U.S. Pat. WO 2005/066117 A1, 21 Jul 2005.

27. S. Mantegazza, P. Allegrini and G. Razzetti, A Process for the Preparation of Entacapone, Eur. Pat. WO 2007/135406 A1, 4 Dec. 2007.

28. A. Kwokal, T. T. H. Nguyen and K. J. Roberts, Polymorph-directing seeding of entacapone crystallization in aqueous/acetone solution using a self-assembled molecular layer on Au (100), Cryst. Growth Des. 9 (2009) 4324-4334; DOI: 10.1021/cg900105u.

29. O. Glatter and O. Kratky, Small Angle X-ray Scattering, Academic Press, London 1982.

30. M. Ratkaj, T. Biljan and S. Miljanić, Quantitative analysis of entacapone isomers using surface-enhanced Raman spectroscopy and partial least squares regression, Appl. Spectrosc. 66 (2012) 1468-1474; DOI: 10.1366/12-06752. 